\title{
A Case Study of a Role-Play Course for Undergraduate Airline Service Students
}

\author{
Mijin Ra, Ph.D. \\ Department of Airline Service Management, Jeju International University, Jeju, Korea
}

Received: November 23, 2020

Revised: December 7, 2020

Accepted: December 7, 2020

\author{
Corresponding Author \\ Mijin Ra \\ Department of Airline Service Management, \\ Jeju International University, 2870 516-ro, \\ Jeju 63309, Korea \\ Tel: +82-64-754-0200 \\ Fax: +82-64-702-0933 \\ E-mail:mijin.ra@gmail.com \\ ORCID
}

https://orcid.org/0000-0003-3812-0561

\begin{abstract}
This study utilizes the image contents, one of the social interaction activities, in role-play. The one-semester class results were used for analysis to prepare teaching-learning plans for the department of aviation services. This study helped students in the Department of Aviation Services understand the airline cabin organization and examined whether it would help them understand the airline cabin organization and examine whether it would help them communicate with customers. In role-play classes, learners or groups of learners use role-playing dialogues to create role-plays and create communication situations similar to the real world.
\end{abstract}

Keywords: Organization and administration, Education, Teaching

\section{INTRODUCTION}

An essential part of the aviation service department' s curriculum is the ability to communicate with customers in the air cabin service situation. However, many aeronautical service college students suffer from a lack of understanding of airline cabin organization and customer service situations that they have not experienced before. Therefore, it is necessary to create a para-communication situation and educate it to create the same environment as the communication situation with customers in the airline cabin organization. This is especially helpful in the current situation where college students who are not yet experienced in social studies are asked in the role-playing communication format with customers even during interviews for employment by airlines.

The role-playing method of image content utilization is a learner-centered class method, not the traditional teaching-led class method. Undergraduate students in the department of aviation services experience imperson- ation as real situations without experiencing communication with customers using airlines, thereby gaining tacit knowledge of the communication situation with customers.

Unlike explicit knowledge, which is the knowledge you learn by reading a book or listening to a lecture, tacit knowledge can be best learned through an immersive experience. It is also the knowledge that is an instructor and challenging to convey to learners. Therefore, by utilizing role-playing that is valuable in education, students can learn about aviation cabin organization and improve communication skills with customers in 'Role-play', a third-year course in four-year college aviation service through actual classes for one semester.

\section{II . THEORETICAL BACKGROUND}

\section{Contextual learning theory}

Situational learning is based on the argument that the learner's lessons should be based on specific and diverse cases that can occur in real-life task situations, contexts, 
and situations. This is because constructivism, which emphasizes individual learners' experience and interest, emerges as a new theory of learning, which is developed based on this. The situational learning theory is that human thinking is limited by the context in which it occurs. Emphasize that all knowledge must be taught through the contextual context in which it is actually occurs.

The characteristics of this situational learning theory are as follows.

First, context is important. Situational learning theory begins with recognizing that human thinking is limited by the context in which it occurs [1]. Therefore, context is a prerequisite for contextual learning theory. When constructing learning content and environment, context should be considered first. Researchers in contextual learning theory suggest that real-life contexts enable students to link learning content to their personal experiences and practical needs, motivating them to learn and make knowledge more meaningful and easier to understand.

Second, we have to emphasize collaboration-based learning. Significant learning is possible through helping learners cooperate with each other through social interactions with other learners and providing social support while observing and imitating each other's knowledge and skills [2]. In other words, learners can experience learning from their self-centered thinking through interaction with others.

Third, learning occurs when learning with real tasks in real-world situations [3]. Knowledge in the context of contextual learning theory is contextual and can be generated within the context of the task, context and culture in which it is to be used.

\section{The concept of role-play}

Role-play is the exercise of students' assigned roles in a given situation, where they practice expressions and attitudes appropriate for that situation. Looking at existing research on role-plays, Livingstone (1983) distinguishes role-plays from play-acting, group work, and dialogue work to consider aspects of actual role behavior that may be needed outside the classroom. To allow students to practice their language [4]. Larsen-Freeman (2000) suggested that role-play plays a vital role in communication pedagogy by providing learners with the opportunity to play different roles in different situations [5].

Ladousse (1987) described role-play by dividing them into roles and plays. Roles are the assignment of learners to specific tasks in a particular situation, and play is to allow students to perform their roles in the most enjoyable environment possible [6]. In the end, role play implies that learners are given a role to make their interactions pleasant by assuming a situation that exists in reality.

Bruner (1990) states that the most basic form in which humans can give meaning to themselves and others' actions is a dialogue in role-plays, revealing his back and seeing other people's minds at the same time [7].

Livingstone (1983), on the other hand, divided roleplays into situational-only roleplays and role-plays with fingerprints and dialogues [4].

In the same vein, Littlewood (1981) categorized the types of role-play into controlled and creative role-play. Controlled role-plays included performing memorized dialogues, contextualized drills, cued dialogues, role-play, and creative role-plays. Improvisation [8].

Although role-plays have educational effects that can be applied to communication-related situations by playing various roles in various situations, existing studies using role-plays are mainly used for language education such as native language and second foreign language.

Suppose we could combine the advantages of this roleplay with a college student in the department of aviation services aiming for employment as an airline. In that case, you you can create a quasi-communication situation where you can directly experience communication with customers. It is worth using in this respect, and the educational effect can be expected to be high.

\section{TEACHING-LEARNING METHOD USING ROLE-PLAY IN AVIATION SERVICES}

\section{Teaching-learning model for role-play}

Role-playing, which is a part of practical training among the majors of aeronautical service students, gives students the ability to communicate by giving situations and roles that can occur in various communication with actual customers. The goal is not only to improve the quality of learning but also to increase learning efficiency. Therefore, when conducting teaching-learning activities using role-play, the current level of learners should be taken into consideration, and in order to enhance the learning effect, it should be constructed based on the pre-role stage, process role stage, role and post-role stage.

Given these points, this study proposes the role-use 
teaching and learning model of role-playing in the University's aviation service department's practical field subjects based on the role-playing models of scholars mentioned above.

As shown in Fig. 1, the role-play teaching and learning design of the role-play class for the 3 rd grader of the major courses in the aviation service department of the $S$ University has three phases. In other words, pre-learning is conducted in the pre-role stage to help learners understand what they are learning. In the second stage of role-play demonstration, role play is performed after prelearning using contents. In the third stage of role-play, the teaching and learning process is completed through feedback and evaluation of role-play performed by learners.

\section{Demonstration course of role-play class}

\section{1) Role-play preparation steps}

Looking specifically at the teaching and learning stage of customer service communication that corresponds to the stage of role-play, learners are motivated to learn the customer service situation. At this stage, the instructor's practical experience and the contents of students' previous learning can be used, but various video contents were used in this class. The instructor can suggest to share and share various contents such as movies, dramas, and documentaries that can indirectly experience the customer service communication situation during the first session. Through this, it is crucial to secure variety of contents to enhance the lessons' efficiency by activating the schema of learners. In this case, the instructor can lead the learners to motivate themselves by brainstorming or freely speaking and asking about the subject to not be focused only on the specific environment's customer communication situation.

Using this content, you will ultimately be able to practice applying and contextualizing your customer service language and help you understand customer service situations that you have not experienced.

\section{2) Stage of execution of role-play}

At the end of the role-play phase, it takes place in two phases of activity. In this stage, the core activity is to perform the actual role play based on the learning contents using the role play stage's contents. First, activities to understand the situation of role-playing are carried out, and groups of about 3 to 5 people are organized, and then role-plays are selected and roles are set to complete the role-play script.

The following is an example of students completing the script by using video content (Fig. 2).

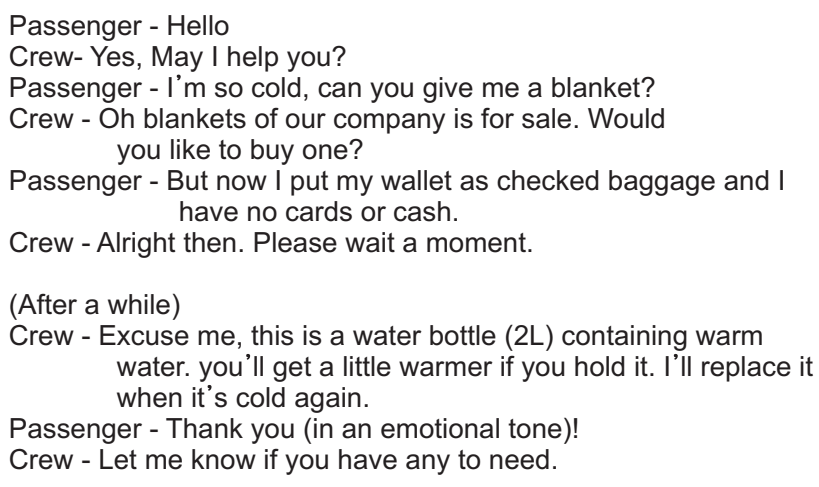

Fig. 2. A series of dialogues written by students.

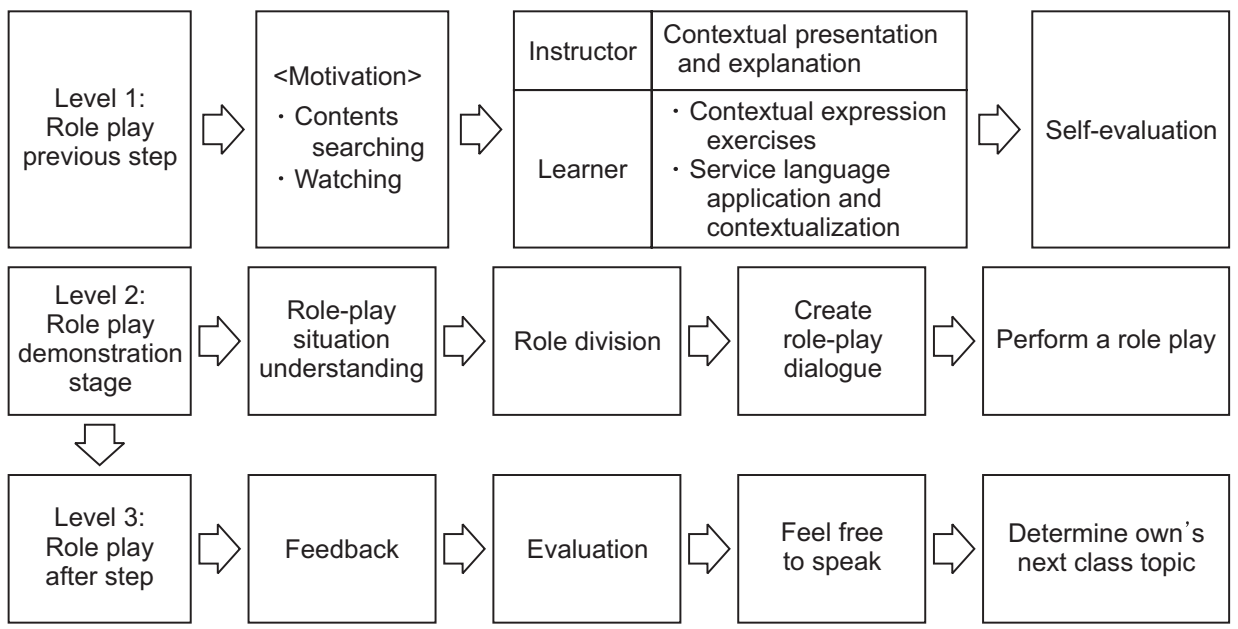

Fig. 1. Service communication role play teaching/learning model. 
The situation was set up in in-flight problem solving for passengers in need of a blanket, but differently from the passenger's point of view. This is also connected to the problem-solving situation, where students refer to various video contents and use the contents as they are or modify the script creatively as in the script above. By doing this, you could learn how to respond to the various service needs of passengers.

At this time, the role-play script may be composed together and determined. When the script is complete, learners perform role-plays based on scripts they have completed.

At this stage, learners are not yet in that role, so it is necessary to induce active and natural immersion in their roles. Role-plays are played in as many groups as possible. It is different from merely having a fixed role in video content. Both members alternate between the role of the crew serving the service and the passenger receiving the service. This can deepen what you learn in role-plays and encourage situational feedback between role players.

\section{3) Role play evaluation and feedback steps}

Stage 3, after the role-play demonstration, is a postrole stage activity that provides feedback and evaluation. This stage involves evaluation and feedback throughout the entire process, from the role play's preparation to the demonstration. You evaluate and provide feedback on a group-by-group and overall basis to ensure that learners understand and act appropriately, including error corrections to the roleplay scripts they have completed.

In particular, we could film the demonstration process, and all the members participating in the class at this stage present their opinions. Participants will self-assess first, followed by what other groups have done well and what they will supplement. Finally, the instructor evaluates in a general manner and concludes the role-playing process.

\section{CONCLUSION}

This study aims to improve the course learning outcomes of the aviation service department by using the composition and situation of role-play in connection with the video contents. Although role-playing is a very suitable teaching method for lectures in this field, it is considered that there are many supplements due to the lack of research on it.
Role-playing needs to be closely planned in stages. $\mathrm{Ne}$ glecting a single step, the details in it is less efficient in the whole process. In particular, since there are many areas in which students take the lead, instructors should understand not only the design of the class but also the qualities of the students, to be fully aware of the role play and to help them indirectly. In the case of video content search, it is good to consider how students accumulate the reference data and manage it as a content data type and use it for future classes. In addition to the prepared scripts, it is also considered a way to improve the role player's ability to solve problems immediately by instructing the instructor during the role-play.

In role-playing classes, students showed positiveness and vigor that was not seen in regular classes. Also, during the role-play, ideas were presented continuously, and students showed their critical acceptance. Considering that students can be the subjects leading their learning rather than becoming objects in learning, it is expected that classes using role-plays will continue to be used as effective teaching and learning methods. In this regard, I hope that the lecture examples in this study will contribute to the development of this field.

\section{CONFLICTS OF INTEREST}

No potential conflict of interest relevant to this article was reported.

\section{ORCID}

Mijin Ra, https://orcid.org/0000-0003-3812-0561

\section{REFERENCES}

1. Choi JI, A Study on the Composition of Learning Contents, the Role of Teachers, and the Evaluation Principle According to Contextual Learning Theory, Pedagogy Research 1997;35:213-239.

2. Choi SK. The Effect of Algorithm Learning through Anchor Class on Problem Solving Ability of Elementary School Students, Korea National University of Education Graduate School, Master's Thesis; 2012.

3. Kang IA. Characteristics and Differences of Constructivist Models-Focused on Cognitive Apprentice Theory, Situational Learning Theory, and Cognitive Flexibility Theory, Educational Technology International 1996;12:1-19.

4. Livingston. Role Play in the learning, London: Longman; 
1983.

5. Larsen-freeman. Techniques and principles in language teaching, Oxford University; 2000.

6. Ladousse. Role Play-Resource books for Teachers, Oxford University Press; 1992.
7. Bruner. Acts of meaning, Cambridge MA, Harvard University; 1990.

8. Littlewood. Communicative Language Teaching-An introduction, Cambridge University Press; 1981. 